\title{
Geotechnical considerations for the stability of open pit excavations at mine closure: some scenarios
}

\author{
I de Bruyn SRK Consulting (Australasia) Pty Ltd, Australia \\ D Prado SRK Consulting (Australasia) Pty Ltd, Australia \\ J Mylvaganam SRK Consulting (Australasia) Pty Ltd, Australia \\ D Walker SRK Consulting (Australasia) Pty Ltd, Australia
}

\begin{abstract}
In the current mining industry climate, early and detailed planning for mine closure is becoming increasingly important. Geotechnical inputs relating to stability of open pit excavations were often limited or cursory in past mine closures. Although broad guidelines based on general observations do exist in some countries, detailed deterministic approaches and design criteria specifically applicable to open pit excavations during mine closure have not been well established. Large open pits may be most sensitive to the economic impacts of geotechnical requirements/constraints for closure, particularly if unduly conservative approaches are employed. It is therefore necessary for these requirements and constraints to be carefully assessed for each pit, and for the most cost-effective measures to be identified. It is important that slope instabilities are well-documented during operations, and that good communication between various technical departments is maintained for closure planning and coordination.

This paper presents examples of several scenarios in which pit slope stability assessment may be required at mine closure. These are focused specifically on the long-term stability of the open pit excavations, not the stability of any adjacent structures. The paper does not attempt to propose a set of guidelines but discusses techniques that may be used for assessment under various scenarios. Topics include estimation of rock mass degradation over time, assessment of long-term instability around pits, evaluation of slope buttressing options, and determination of exclusion zones around pit crests (and in-pit floors that must remain open to access).
\end{abstract}

Keywords: geotechnical, open pit, closure

\section{Introduction}

A changing mining industry climate is resulting in a greater focus on geotechnical aspects affecting the stability of open pit slopes after closure. Where previously a primary consideration was in estimating zones of exclusion around pits crests, there is now an increasing need to conduct detailed site-specific assessments to support appropriate closure strategies with regard to long-term pit wall stability. There is often a need to present clearly-reasoned geotechnical arguments to support specific plans. As there is little well-documented geotechnical design guidance in this respect, the geotechnical engineer is required to make good use of the comprehensive geotechnical 'toolbox' and apply sound judgement. The main question would be: 'what am I trying to achieve?'. To present a few examples, it may be necessary to:

- Determine whether long-term instability is likely to impinge upon infrastructure elements around the pit crest, such as plant sites, waste dumps, tailings dams, roads etc. If the answer is yes, it first must be considered whether this actually constitutes a problem; a decision process which is usually outside the geotechnical realm and may well depend on the specifics of the site - what is considered necessary from the point of view of the regulatory authorities, company compliance, outside parties and risk of environmental degradation/contamination. 
- Develop strategies that will prevent or restrict potential long-term instability such that exclusion zones can be reduced in extent, or identify measures that will significantly reduce the risk of pit slope instability to acceptable levels in the long-term.

- Identify the extent of exclusion zones within pits (on the pit floor) - where maintenance of public access through the excavation after closure may be a requirement. This is a possibility in large pits located in river valleys or areas of traditional accessways, or in quarries near cities.

In many cases, the cost of introducing measures in the short-term that may help to mitigate or address potential long-term issues post-closure must be weighed-up. The following sections discuss some geotechnical considerations for open pit slope stability after closure, illustrating these with examples. No attempt is made to propose a set of guidelines, rather this presents a discussion of techniques that may be used for assessment under various scenarios.

\section{Examples of existing guidance in Australia}

\subsection{Department of Mines and Petroleum abandonment bund guidelines}

A commonly-used method for the identification of exclusion zones around open pits is presented in the document: 'Safety Bund Walls Around Abandoned Open Pit Mines - Guideline, Revision 1', by the Western Australia Department of Mines and Petroleum (Department of Mines and Petroleum, Western Australia [DMP] 1997), which is now the Department of Mines Industry Regulation and Safety. These guidelines provide generic design criteria to determine the likely zone of instability (Zol) for long-term post-mining instability; i.e. the area designated as the potentially unstable pit edge zone. This is used for defining the zones outside of which it is usually necessary for key infrastructure elements to be situated. As a good example of an empirically-based generic guideline that is useful as a first-pass approach to assessing potential Zol, its use is described further.

The case history data from slope failure and tension crack measurements around open pits in Western Australia suggest that the maximum area of potentially unstable rock mass for failure through each class of rock can be defined by two separate design angles:

1. $25^{\circ}$ for weathered rock (this includes saprolite and transitional/saprock materials; i.e. all materials up to moderately weathered grade).

2. $45^{\circ}$ for unweathered rock (this should include rock of slightly weathered grade, that exhibit only joint oxidation but no weathering of groundmass).

This defines the maximum extent of the zone of potentially unstable/distressed rock mass (though not necessarily failed rock mass) and has therefore been developed with a generally conservative mindset. an abandonment bund should be constructed at least $10 \mathrm{~m}$ outside the Zol, as illustrated in Figure 1.

Where pit walls have complex shapes involving numerous ramps, inter-ramp slopes of varying angles, and a complex or highly variable weathering profile, care and must be taken in the determination. Where local variations in-pit wall geometry intersect the projected line of potential instability (e.g. a wide berm or haul road), then the width of the potentially unstable pit edge zone is determined using the abovementioned angles but from the toe of the upper inter-ramp slope section. An example of this is presented in sectional views in Figure 2. Within the unweathered rock, $45^{\circ}$ projections have been made from the base of the overall pit slope and from the base of each inter-ramp section, around the entire circumference of the pit. These were projected up to the base of weathering. As a result of the complex geometry of the pit, with the pit ramp spiralling downwards, the individual projections present a complex pattern in 3D. The final projected position (circumference shape) at the base of weathering has been defined using the outermost projected position at all points around the pit. This shape was then projected to the surface at a $25^{\circ}$ angle within the weathered material. The circumference at the surface (somewhat smoothed) represents the expected limits of the potentially unstable edge zone around the pit. Figure 3 presents a plan view of the pit, as used for the 
assessments described, with the projected positions of the required abandonment bunds shown relative to the nearby infrastructure.

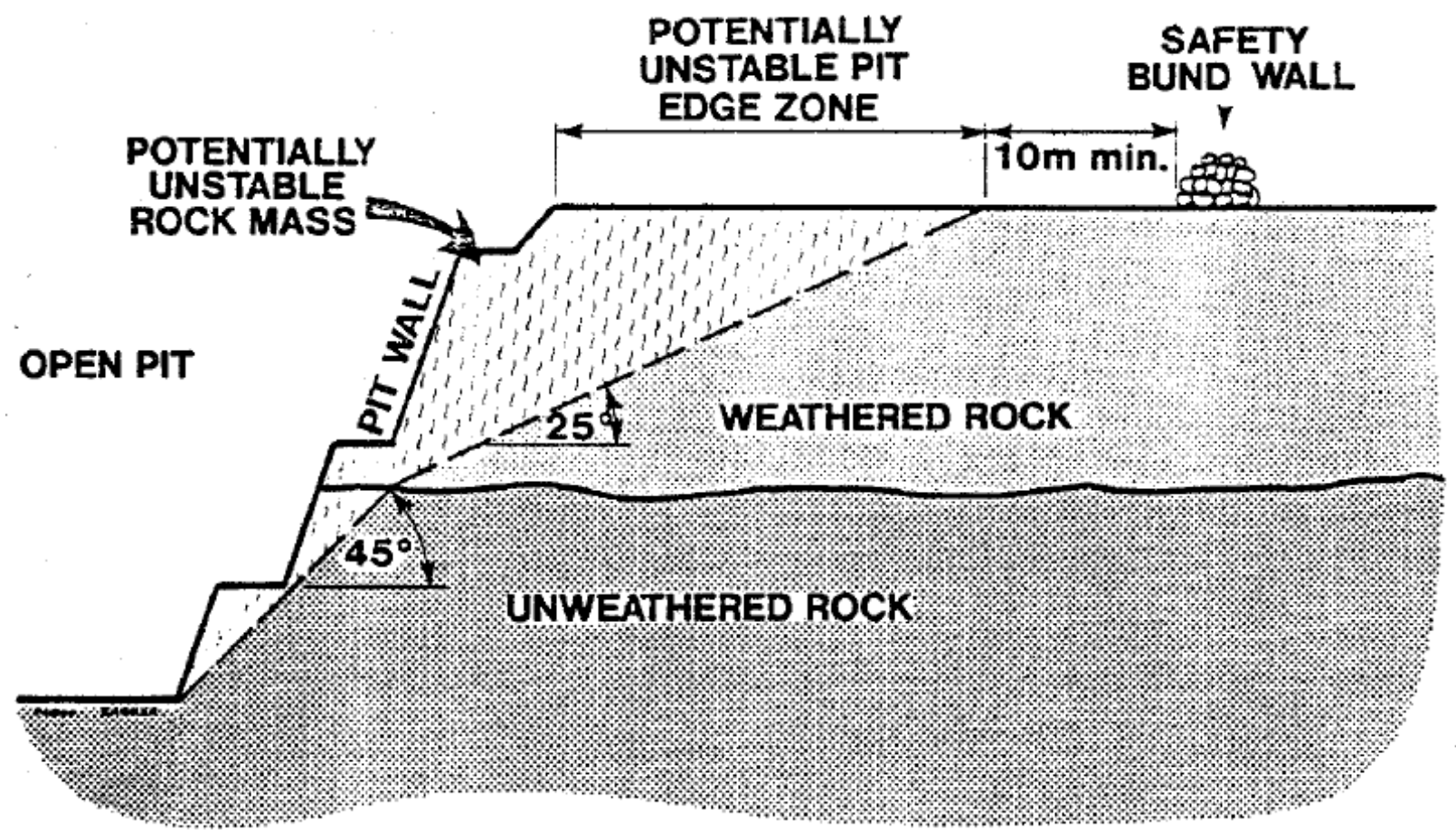

Figure 1 Cross-sectional illustration providing an example of the delineation of the potentially unstable edge zone and the positioning of the abandonment bund (from DMP 1997)

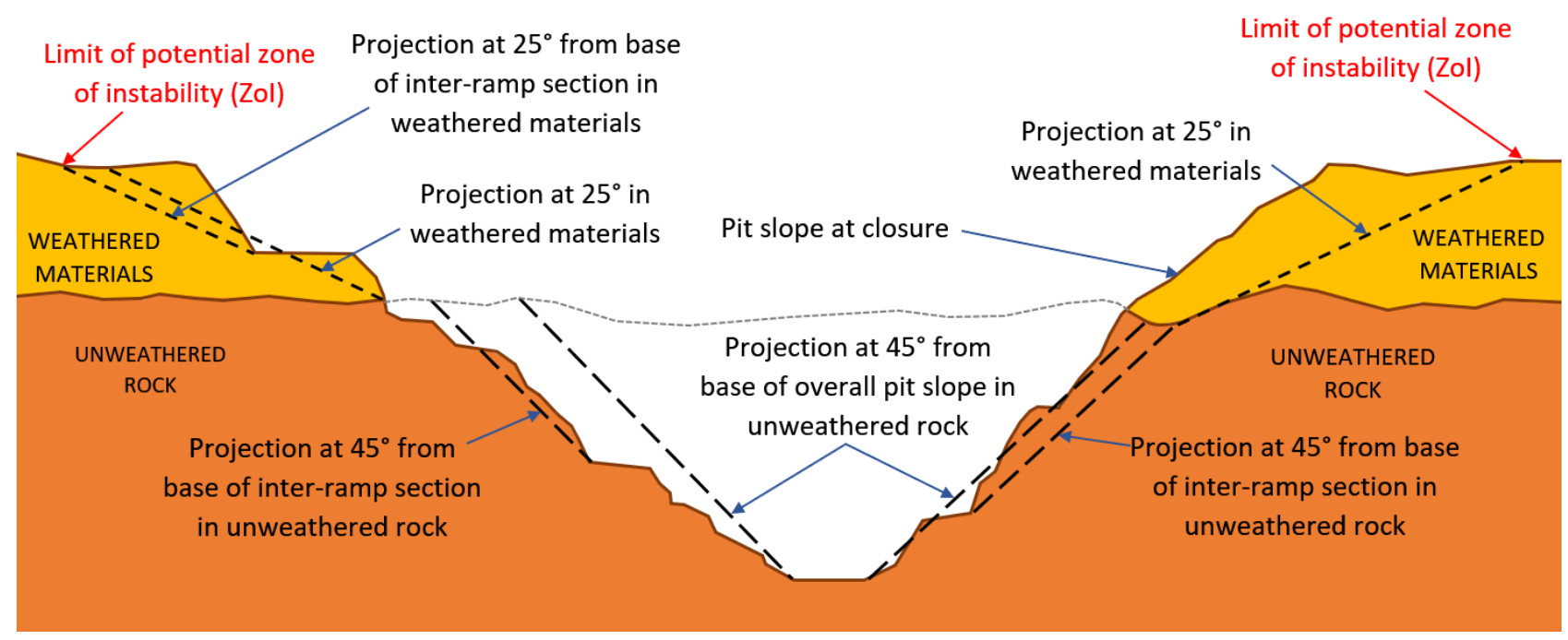

Figure 2 Sectional view through the final pit showing the projected position of the potentially unstable edge zone (zone of instability - Zol) surrounding the pit at surface 


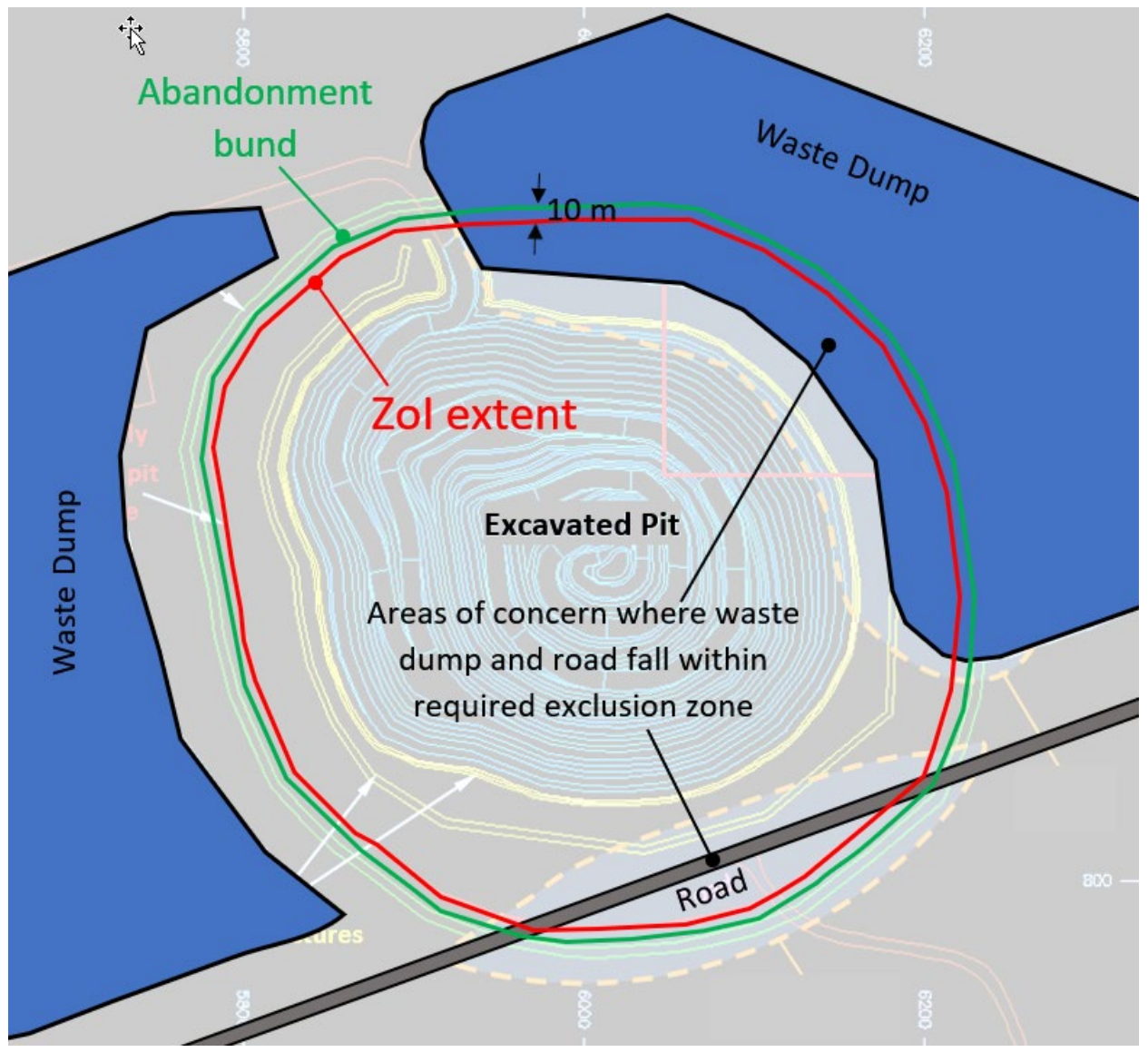

Figure 3 Plan view showing the projected position of the limits of the potentially unstable edge zone, and location of the abandonment bund, with reference to waste dumps and a public road

\subsection{Department of Minerals and Energy geotechnical considerations in open pit mines}

The Western Australia Department of Minerals and Energy (DME, which became the DMP) document 'Geotechnical considerations in open pit mines - Guideline' (Department of Minerals and Energy, Western Australia [DME] 1999), presents guidelines on range of geotechnical mining issues. However, it does not present any detailed guidance on long-term stability assessment after mine closure.

\subsection{Earth Resources guidelines}

The Earth Resources (2019) (part of Victoria State Government) document 'Guidelines for the assessment of geotechnical risk in open pit mines and quarries' presents as a guideline for the horizontal extent of the Geotechnical Risk Zone (GRZ) around a pit crest. This is defined as four times the height of the final (uppermost) batter (bench). If this batter is less than $20 \mathrm{~m}$ in height, then the GRZ is defined as three times the height of the final batter, plus $20 \mathrm{~m}$. The guideline is not specific to slope instability in the long-term after rock/soil mass degradation, however.

\subsection{Guidelines for open pit slope design}

Geotechnical considerations for open pit closure in the global industry standard reference 'Guidelines for Open Pit Slope Design' (Read \& Stacey 2009), are addressed in Chapter 14: Open Pit Closure (van Zyl 2009).

The chapter outlines the following typical steps in developing an open pit closure plan:

- Develop closure goals and criteria, with local community and other stakeholder engagement. 
- Incorporate closure planning requirements in geological and hydrogeological models to assess the final condition of the pit walls, surface water, groundwater and surrounding areas.

- Perform site characterisation to address closure goals and criteria and address data gaps.

- Develop closure plan with specific consideration of pit lake formation, water quality, surface groundwater, geotechnical stability of walls, public access, acid rock drainage and leachate production.

- Implement closure activities during mining.

- Review and update the closure plan on a regular basis.

- Prepare final closure plan for implementation at least 2-8 years before close.

Geotechnical-related items listed as needing to be addressed in site characterisation for closure include the following:

- Site hydrogeology including surface water and groundwater conditions, and the formation of a pit lake after mining ceases.

- Site geochemistry, including weak zones which may degrade or erode, presence of sulphides and major metals, leach characteristics, quality of runoff and groundwater, and quality of the water in the pit lake.

- Geotechnical conditions including shear strength and degradation of both intact rock and structure, influence of large-scale faults on pit wall stability, operational effects on pit wall stability.

The influence of geotechnical conditions on long-term pit stability is discussed further in the following sections of this paper.

\section{Detailed assessment of likely instability}

The identified extent of the potentially unstable edge zone by empirically-based methods should be considered indicative only. These methods provide only generic design criteria that allows for the normal variation of several factors for which detailed information is not always available. The actual performance of the pit slopes in the long-term will depend on the particular site conditions (groundwater conditions, rock strength and durability) and likely mechanisms of failure. In areas where weak rock is susceptible to relatively rapid deterioration, areas that may be adversely affected by groundwater rise, where critical fault structures are located near the margins of the pit, or where rock mass fabric plays a key role in the instability mechanism, it will be prudent to perform stability assessments to confirm the likely position of the Zol. For certain abandonment proposals, analyses may be required to demonstrate the low risk and/or limited extent of long-term instability of the rock/soil mass around the pit crest. In such cases, specific geotechnical studies are required to establish abandonment criteria applicable for each particular case.

\subsection{Identification of critical failure mechanism}

As for operational open pit slope design, identification of the critical failure mechanism that will govern largescale slope instability is essential, as this will also control the closure requirements. A well-documented database and record of slope failure during mining operations will help in predicting instability over the longterm. Failure may be structurally controlled; by faults, ubiquitous rock mass fabric or a combination of both. Alternatively, where the rock mass is relatively homogeneous, it will be controlled by the general shear strength, and potentially the tensile characteristics, of the rock mass.

The effects of failure mechanism can be seen in natural slopes that have been developed over very long periods of time. Lower natural slope angles will have developed due to ongoing rock mass failure in weaker rock masses (or sliding along low-angle structural fabric). Slopes in very strong rock masses are generally much steeper and 
largely exhibit structural controls on slope failure. Sub-vertical structural sets facilitate steep sliding and toppling failures, allowing for steeper slopes. Moderately-dipping structural sets facilitate wedge and sliding failures, and the dip angles of these sets is likely to govern long-term slope angles. Sub-horizontal structural sets contribute to the blockiness of the rock mass and may facilitate other structural failures. All open structures may facilitate groundwater movement and slope deterioration, which can affect stability.

\subsection{Considerations for rock mass deterioration}

\subsubsection{General considerations}

Few studies regarding long-term rock mass degradation in open pit slopes are publicly available. The Guidelines for Open Pit Slope Design (Read \& Stacey 2009) recommends review of several key considerations for the long-term after closure and pit abandonment, many of these relating to changes that are expected to occur in the rock mass and boundary conditions that influence the geotechnical stability of the pit walls in the medium and long-term. The geotechnical stability of the pit walls after closure are mainly influenced by the following factors:

- Weathering (deterioration from exposure) and slaking.

- Shear strength changes in-pit wall materials resulting from reduction in intact material strength and reduction in shear strength of fractures and major structures (faults and shears).

- Rock mass degradation as a result of stresses.

- Stress relief - resulting in instability and/or ravelling.

- Hydrogeological changes (e.g. re-pressurisation of slopes due to cessation of dewatering and pit lake development).

- Seismicity.

- Loss/deterioration of controlled surface drainage, leading to re-pressurisation and/or erosion.

- The presence of voids from underground mining (if present).

It is often reasonable to assess these factors within a 200-300 year post-closure period, however consideration of longer periods of time may be necessary. The selection of seismic loading inputs and the possible effects of erosion due to flooding events (where relevant) are important external considerations that may require careful consideration and inputs from specialists; however, these are not the focus of this paper.

The degradation of the rock mass that is likely to occur over time is difficult to quantify. Assumptions must largely be based on field or laboratory testing (often of limited applicability for the long-term), current geotechnical properties, limited case studies, past experience observing deterioration, extrapolation and engineering judgement. In short, assumptions concerning degradation are subjective, and there are few published examples that can be confidently followed.

The overall effect is that the pit walls may become distressed and ravel or fail over time, and in extreme cases major failures of the pit walls can occur. The failed material ('talus') may accumulate in the pit lake, possibly impacting pit lake water quality or possibly creating a wave in the pit lake. Industry accepted detailed empirical or deterministic approaches applicable to the estimation of talus volumes have not been established. Identification of principles for long-term deterioration and talus estimation is a challenge, and the approaches utilised provide only indicative results/ranges which can be used to guide sensitivity analyses.

To attempt to best estimate the deterioration of pit slopes, engineering judgement is used to identify the likely deterioration in the various components contributing to rock mass strength, including the intact strength, the joint properties and the joint spacing. These can be assessed using weathering, durability and Geological Strength Index (GSI - which evaluates rock mass blockiness and fracture conditions) data available for the rock mass at the time of pit design - to provide amended inputs for stability assessment. Weak or 
weathered rock is likely to deteriorate more rapidly than strong, unweathered, good quality rock mass - so this must be taken into account in the downgrading of individual factors. The presence of groundwater will also play a role.

- Potential reduction in intact strength could be assessed from weathering data and slake durability testing and/or accelerated weathering tests conducted in the field.

- Potential reduction in joint and fault shear strength properties should be considered based on the possibility of loss of cohesion and/or friction over time as a result of weathering processes, stress factors and rock mass dilation. It might be judged, for instance, that the cohesion will be lost over time (particularly in closer proximity to the surface or slope face) and the frictional properties of the surfaces will be largely maintained.

- The potential reduction in rock mass shear strength properties must take into account the reduction in intact strength and shear strength of structures mentioned above, whilst also considering potential rock mass dilation, stresses and additional fracturing over time. Depending on the site conditions, it may be assumed that over time a significant percentage of the shear strength of the rock mass will be lost. Where shear strength properties for weak materials such as saprolite are already very low, it might be reasonable to assume that no significant reduction is likely. For saprock (transitional materials), it might be assumed that the shear strength will be reduced closer to that of saprolite, and for unweathered rock it could be assumed that the shear strength will be reduced by a selected percentage (which would be site or domain-specific). Depending on the shear strength model considered, the degraded rock mass shear strengths can be calculated by reducing cohesion (c) and friction $(\phi)$ when a Mohr-Coulomb model is applied, or evaluating the potential degradation of GSI, Disturbance Factor and/or the Unconfined Compressive Strength (UCS or oci) when a HoekBrown (Hoek \& Brown 1988) model is considered. Figure 4 presents a sketch of the reduction in shear strength using the Hoek-Brown Model.

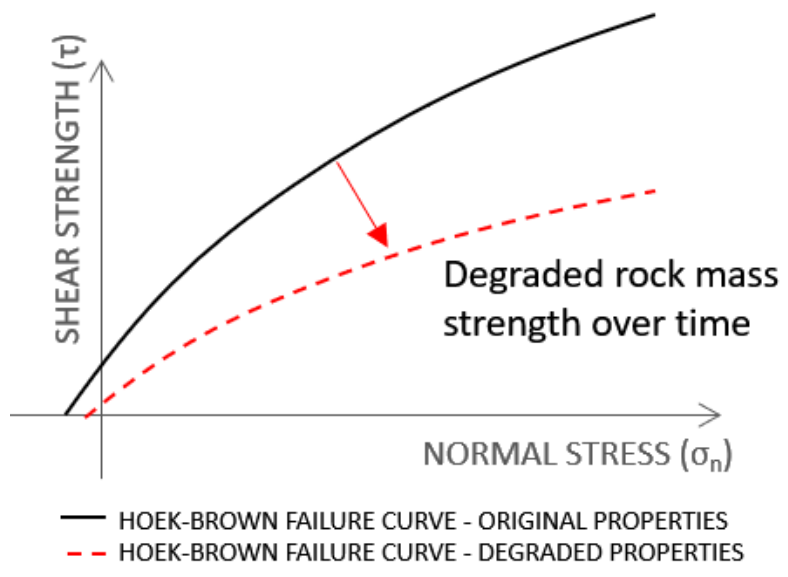

Hoek-Brown criterion:

$$
\sigma_{1}^{\prime}=\sigma_{3}^{\prime}+\sigma_{c i}\left(m_{b} \frac{\sigma_{3}^{\prime}}{\sigma_{c i}}+s\right)^{a}
$$

where

$$
\begin{aligned}
& m_{b}=m_{i} \exp \left(\frac{G S I-100}{28-14 D}\right) \\
& s=\exp \left(\frac{G S I-100}{9-3 D}\right) \\
& a=\frac{1}{2}+\frac{1}{6}\left(e^{-G S I / 15}-e^{-20 / 3}\right)
\end{aligned}
$$

Figure 4 Example of the Hoek-Brown failure curves for original properties and for degraded properties

For a Hoek-Brown shear strength model, consideration could be given to a reduction in GSI (to account for rock mass deterioration, as illustrated in Figure 5) and an increase of Disturbance Factor (D) to account for long-term rock mass dilation and fracturing due to changes in stress. As an example of the latter adjustment, Figure 6 compares the change in shear strength for two different rock types, for which $D=0.7$ was used for operational conditions and for which $D=1.0$ was considered for the long-term. The shear strength of one rock type is reduced $30-35 \%$ and the other by $20-25 \%$, depending on the normal stresses. 


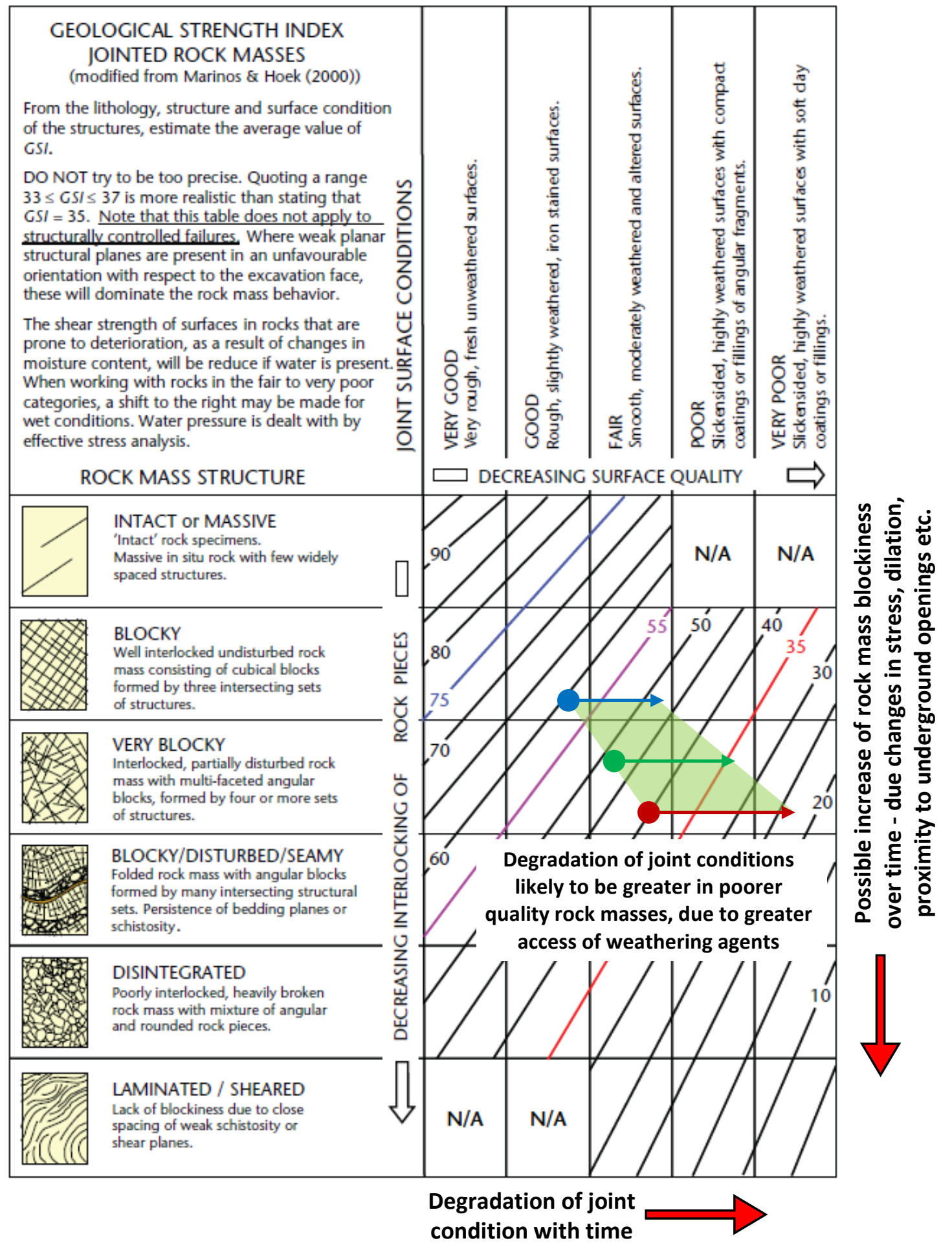

Figure 5 Illustration of reduction in Geological Strength Index (GSI) on the chart modified from Marinos \& Hoek (2000) 


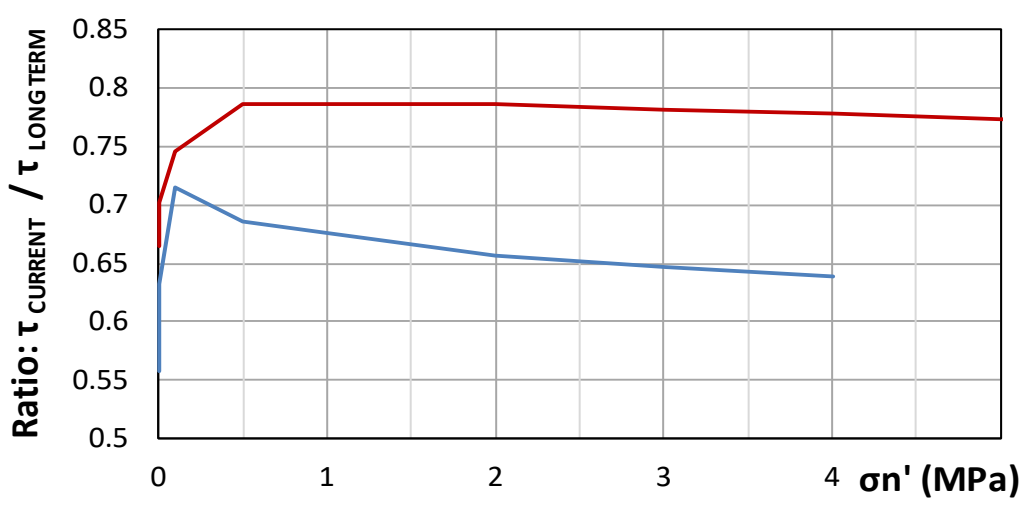

Figure 6 Example of the change in Hoek-Brown shear strength for different rock types as $D$ factor is increased from 0.7 to 1.0

\subsubsection{An example of estimation of long-term rock mass deterioration}

An example of the assumptions made for reduction of properties during a study is described further, in which deterioration over a period in excess of 500 years was considered. Analyses were undertaken using reduced rock mass strength input parameters.

- GSI data suggested the rock mass was generally of very good quality (GSI of 65-75). Based on UCS data, intact strength was well within the strength class of R5 (greater than $150 \mathrm{MPa}$ ) for fresh rock and strength class of R3 ( $35 \mathrm{MPa}$ ) for weathered materials. The rock was indicated to be very high to extremely high durability based on slake durability tests.

- In the long-term, rock masses deteriorate and fail progressively, however large-scale failures are also a possibly. Indicative stability analyses were performed to identify likely instabilities and their extent in the long-term (in terms of large-scale failures) by reducing rock mass parameters (GSI and UCS). Considering changes in weathering, intact strength and joint conditions for this particular site, the GSI was reduced one class ( $\sim 10$ points) for the deterioration in joint condition in the unweathered rock mass; and one to two classes for deterioration in the weathered rock mass. The UCS was reduced by a strength class as a base case.

- Most of the stability analysis results indicated that Factors of Safety (FoS) for potential large-scale instabilities were well above 1, except for the case incorporating seismicity and rise of water levels during pit lake formation. Considering progressive subsequent failure resulting from the steep back scarp angle generated by the analysed initial failure, the long-term failure surface (future slope) within unweathered material was interpreted to extend at approximately a $50^{\circ}$ angle.

- Considering all the scenarios/sensitivities carried out for assessing long-term slope stability and potential talus material volume, the angles indicated in the DMP Guidelines $\left(1997 ; 45^{\circ}\right.$ within fresh rock and $25^{\circ}$ within weathered materials) may be reasonable but are probably conservative within the fresh rock. For the fresh rock, the high strength and high durability indices of the rock mass indicate that, in the absence of unfavourably-oriented structures (faults or bedding), the zone of deterioration contributing to failure and actual talus development is likely to be more constrained. At a minimum, this zone is likely to include all individual benches (i.e. would effectively be defined by the inter-ramp angle). However, this may be optimistic, and the analyses carried out based on judgement/assumptions indicates that an overall angle of $50^{\circ}$ from the toe of the slope would seem to be most appropriate. A comparison of this is shown in Figure 7. 


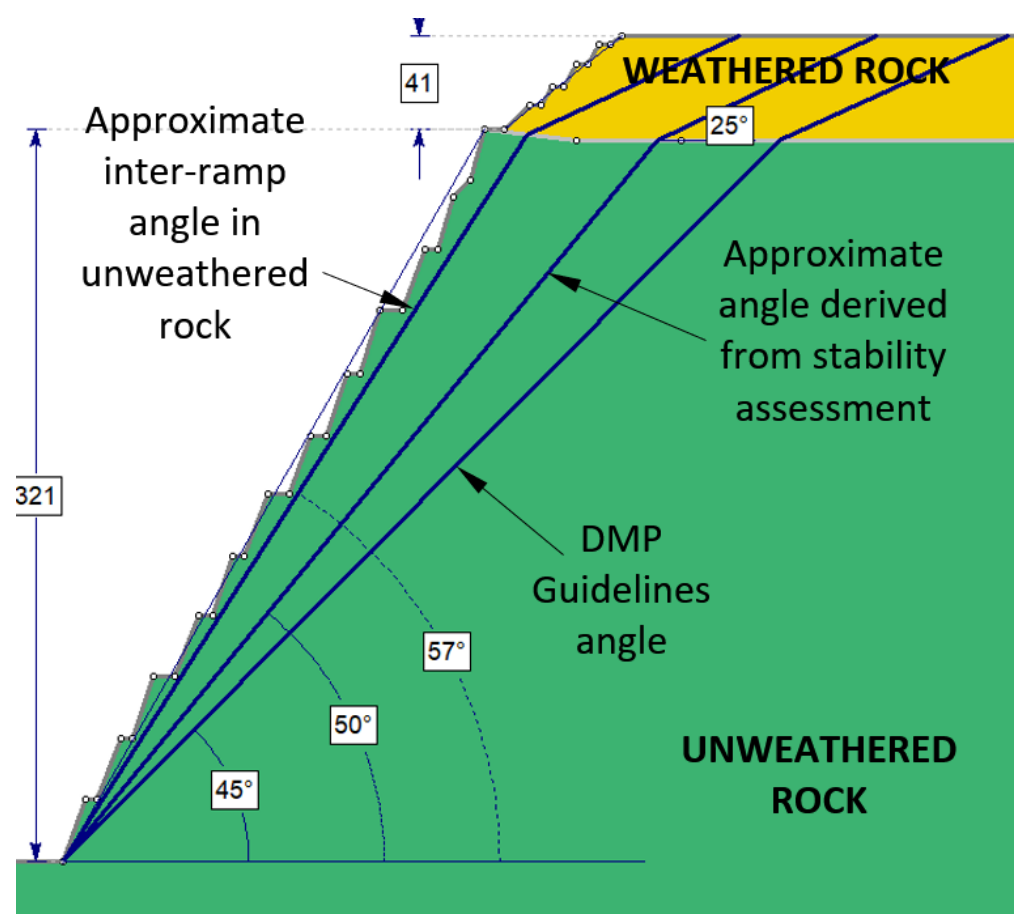

Figure 7 Example showing comparison of possible zones of unstable slope contributing to zone of instability (Zol) and potential future talus development

\subsection{Design criteria}

Design FoS for open pits are commonly defined for mining operations and life-of-mine designs. However, for closure, the literature is not explicit with respect to the criteria for acceptable FoS. Table 9.9 of Guidelines for Open Pit Slope Design (Read \& Stacey 2009), reproduced here in Table 1, suggests target minimum FoS in terms of the performance of pit slopes. The recommended FoS are based on the potential consequences of a pit slope failure under static conditions.

Table $1 \quad$ Extract from Table 9.9 in Read \& Stacey (2009)

\begin{tabular}{cccc}
\hline Slope scale & Consequence of failure & FoS (minimum, static) & FoS (minimum, dynamic) \\
\hline \multirow{3}{*}{ Final Wall } & Low & $1.2-1.3$ & 1.0 \\
& Medium & 1.3 & 1.05 \\
& High & $1.3-1.5$ & 1.1 \\
\hline
\end{tabular}

Similarly, FoS design criteria for open pit design presented in Table 1 of the DME Guidelines (1999). In most cases, the walls carrying major mine infrastructure (Wall Class 3 in Table 1) are likely to present the most appropriate case for pit closure (for which a FoS $=1.5$ is stipulated as the minimum design criterion). Wall Class 4 (with criterion of FoS $=2.0$ ) will be more applicable where pit walls are adjacent to public infrastructure.

Appropriate design acceptance criteria for pit slope failure for closure (where pit slopes are not adjacent to public land or infrastructure) could be defined as follows:

- Where a predicted (analysed) failure zone intersects adjacent sensitive infrastructure elements or the minimum $10 \mathrm{~m}$ standoff distance therefrom, a FoS of $\geq 1.5$ should be achieved under static conditions and a FoS of $\geq 1.1$ should be achieved under dynamic conditions (taken as the upper bound of the FoS range for high risk for slope stability in the table above). 
- Where a predicted failure zone is of limited extent such that it does not intersect the sensitive infrastructure elements or minimum $10 \mathrm{~m}$ standoff distance therefrom, then the FoS is not important (i.e. failure within this zone is considered to be acceptable over the long-term).

\section{$4 \quad$ Mitigation of long-term instability using buttressing}

If assessments indicate that failure of pit slopes after closure presents an unacceptable risk to nearby infrastructure or for generation of large talus volumes, the occurrence of failure must be mitigated. Ground support and/or maintenance of depressurisation is not an acceptable solution for the long-term. If infrastructure cannot be re-positioned, the use of in-pit buttressing for slope support represents one of the few practical solutions. In-pit dumping measures necessary to reduce the risk or size/extent of failures can be identified using the following steps:

1. Assess in detail the current properties of the materials forming the walls of the pit, and their likely degraded properties in the long-term (both for rock mass and for large structures or ubiquitous defects sets). This will already have been done if detailed stability analyses for closure have been conducted.

2. Identify the most likely mode(s) of failure that are expected to occur in the critical slope sectors, affecting their current and future stability.

3. Assuming that no or very limited re-positioning of material or structures around the pit crest will or can be carried out, determine the position of the abandonment bund(s) that are required and confirm that the Zol can be reduced to accommodate the required abandonment bund position. The outside edge of the abandonment bund and drain must be an absolute minimum distance of $15 \mathrm{~m}$ (including the $10 \mathrm{~m}$ required standoff and $5 \mathrm{~m}$ bund and drain width) from the current pit crest, which in that case assumes the Zol has been reduced to zero.

4. Using the identified critical failure mode(s), determine the position and level of waste material that will need to be dumped against the pit wall to maintain its stability in the long-term (i.e. which will meet the required design acceptance criteria) such that the reduced Zol allows the abandonment bund to be located at the position required. Verify the stability of the pit slope and dumped in-pit waste material in the long-term to allow for the Zol to be reduced as necessary. The stability analyses must be performed using a software/analysis method appropriate for capturing the most likely failure mechanisms (it might not always be possible to use a simple 2D Limit Equilibrium method). The designed slope buttress must ensure either:

- That the FoS for failures that extend outside the required abandonment bund position are $\geq 1.5$; or

- That the extent of any failures with FoS $\leq 1.5$ are reduced in extent such that they no longer extend outside the required abandonment bund position.

5. Consider the stability of the waste rock buttress in the long-term. Although the material used for the buttress will likely be dumped at its current angle of repose, it is possible that this angle will reduce in the long-term as the properties of the waste rock deteriorate. Any significant failure (not merely surficial ravelling) or erosion of the waste buttress in the long-term, reducing its effective width/volume, will reduce its effectiveness as a support measure. This could conceivably result in an increase in the risk of failure of the original slope it is meant to support, such that the acceptance criteria for the closure plan are no longer met. Therefore, it may be appropriate to include a FoS in the waste buttress, which will necessitate the dumping of additional volumes of materials such that the slope can gradually subside to a reduced angle of repose whilst still performing its function. If only fresh rock is used for the buttress construction, steeper buttress slope angles can be achieved than for weathered or mixed materials.

An example of a buttress designed to reduce Zol impingement on a waste rock dump is shown in Figure 8. 


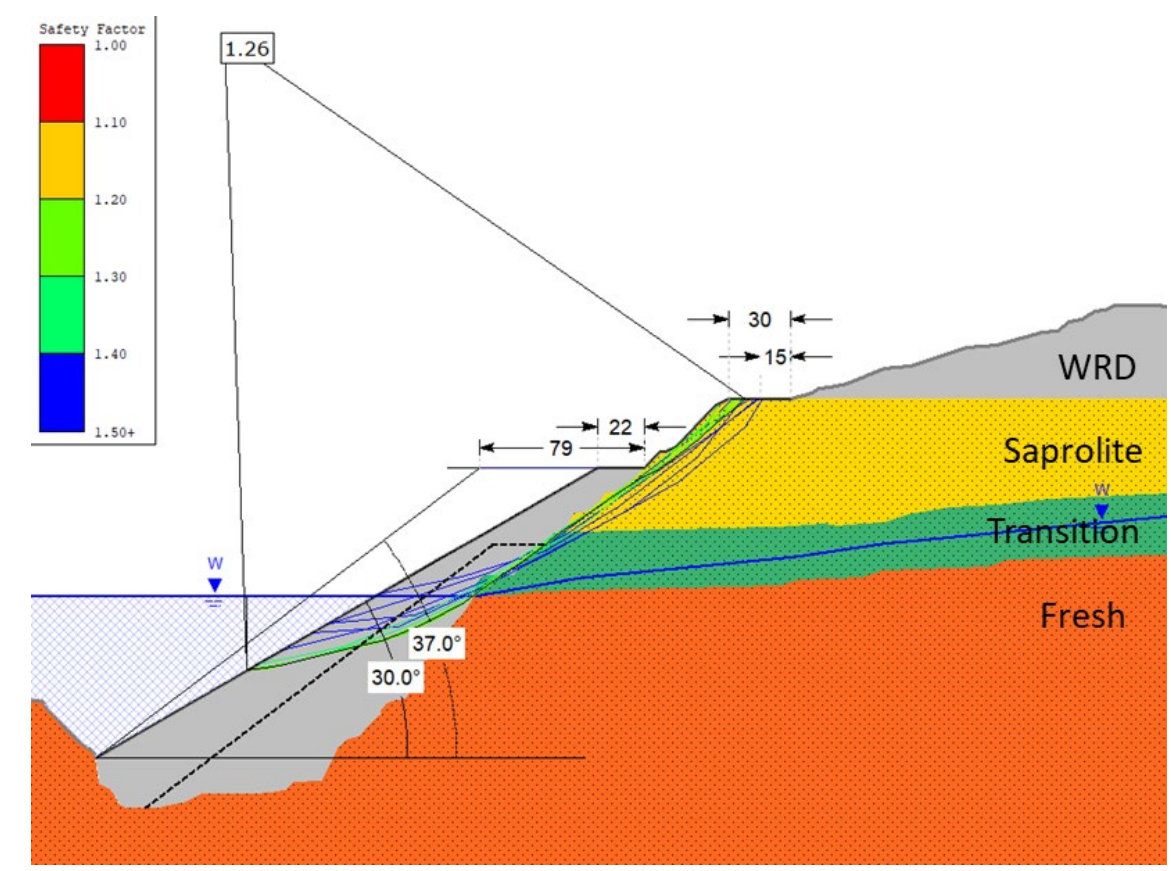

Figure 8 Section example of a buttress design to reduce Zol impingement on a waste rock dump (WRD)

\section{$5 \quad$ Internal pit considerations: rockfall}

In certain circumstances, public access to the pit excavation after closure may be a requirement. This is a possibility in large pits located in river valleys or areas of traditional accessways, or in quarries near cities where the pit can be approached from floor level. In such cases the positions of exclusion zones within the pits, on the pit floor, must be identified. Exposure to rockfall will likely present a primary hazard, necessitating detailed (likely 3D) rockfall assessments.

$3 \mathrm{D}$ rockfall modelling of the pit slopes will provide insights of rockfall behaviour and likely trajectory patterns. The following preliminary workflow can be considered (and modified where necessary during the course of a study):

1. Define preliminary rockfall modelling input parameters for the chosen rockfall modelling software

The main input parameters may need to include the coefficients of normal and tangential restitution, friction angle, variability of surfaces, and rock blocks (size and shape).

2. Perform site trials and model calibration

Site trials would involve personnel conducting rockfall testing onsite, in various areas that have similar characteristics in terms of exposed surfaces (weathering, rock strength, structural orientations, rock block sizes and shapes) to the domains in the slopes being modelled. The data would be used to calibrate the key parameters for the 3D rockfall modelling. The parameters would be adjusted during the subsequent analyses so that the patterns of rockfall trajectory and runouts observed during the site trials are mimicked as closely as possible.

3. Perform model runs (analyses)

Modelling would involve releasing low energy rocks from the pit slope crest of the 3D pit shape. Once the model input property calibrations have been completed, and the input parameters have been finalised with some level of confidence, revised probabilistic modelling runs can be conducted for the areas of interest, and the rockfall trajectories and final resting positions will be forecast.

It is the final resting positions of rocks, and the statistics of the distribution thereof, that will allow for interpretation of the pit floor exclusion zones and thus the positioning of 
abandonment/protective bund locations. An example of 3D rockfall modelling to show rock trajectories and resting positions for the preliminary identification of a bund position is shown in the Figure 9.

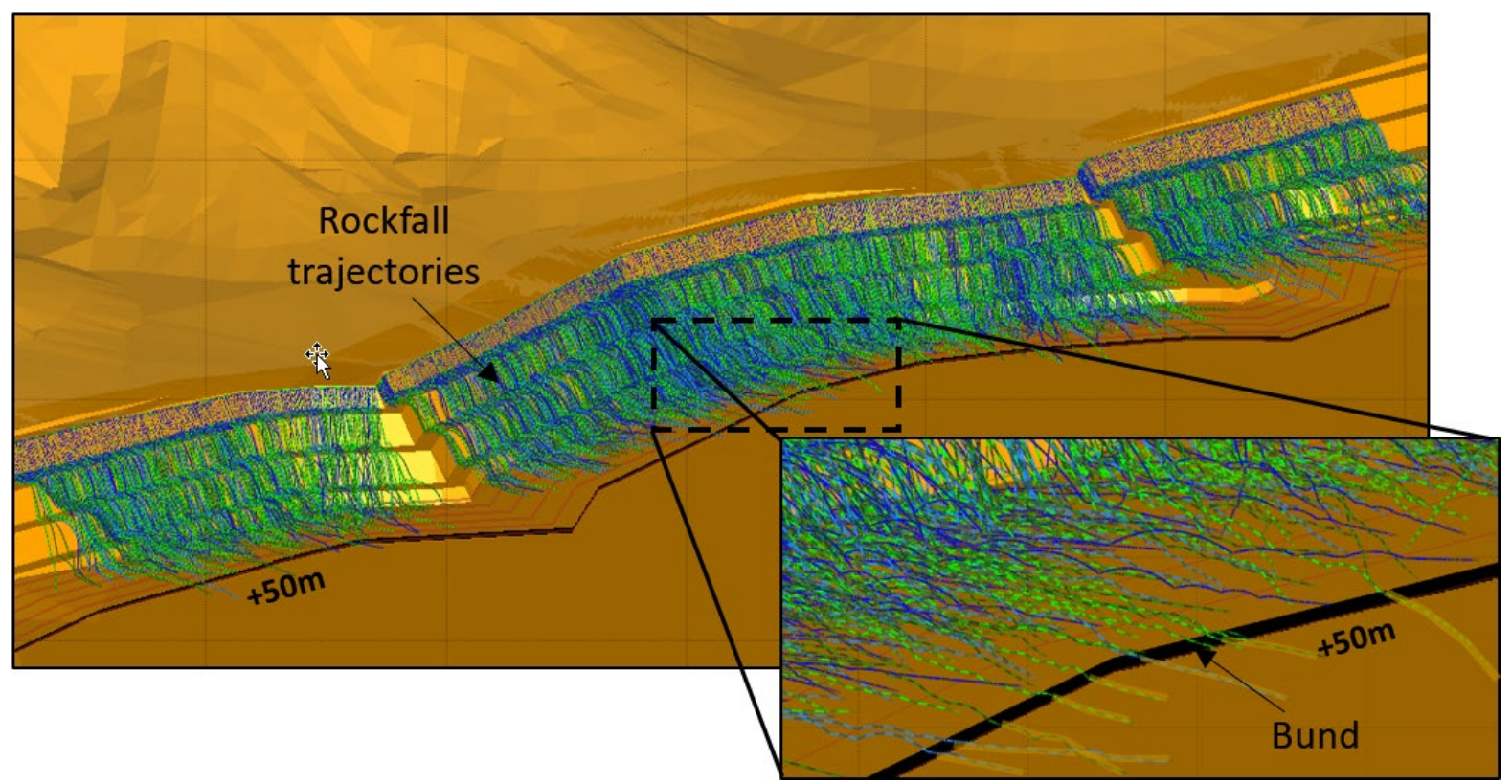

Figure 9 Isometric view showing an example of modelled fallen rock trajectories along an entire length of pit crest; with (inset) an enlarged view showing the selected abandonment bund position approximately $50 \mathrm{~m}$ from the toe of the slope

\section{Conclusion}

In the current mining climate, there is an increasing need to conduct detailed site-specific assessments to support appropriate pit slope stability strategies for mine closure, which may include clearly-reasoned geotechnical arguments to support specific plans. As there is little well-documented geotechnical guidance in this respect, the geotechnical engineer is required to make good use of the comprehensive geotechnical 'toolbox' and apply sound judgement. It may commonly be necessary to:

- Determine whether long-term instability is likely to impinge upon infrastructure elements around the pit crest, such as plant sites, waste dumps, tailings dams, roads etc.

- Develop strategies that will prevent or restrict potential long-term instability such that exclusion zones can be reduced in extent, or identify measures that will significantly reduce the risk of pit slope instability to acceptable levels in the long-term.

The extent of the potentially Zol around pit crests, as identified using empirically-based methods or guidelines, should be considered indicative only. In areas where weak rock is susceptible to relatively rapid deterioration, areas that may be adversely affected by groundwater rise, where critical fault structures are located near the margins of the pit, or where rock mass fabric plays a key role in the instability mechanism, it will be prudent to perform stability assessments to confirm the likely position of the Zol. For certain abandonment proposals, analyses may be required to demonstrate the low risk and/or limited extent of longterm instability of the rock/soil mass around the pit crest.

Identification of the critical failure mechanism that will govern large-scale slope instability is essential, as this will also control the closure requirements. Failure may be structurally controlled, or, where the rock mass is relatively homogeneous, it will be controlled by the general shear strength characteristics of the rock mass. The degradation of the shear strength of the structures and rock mass that is likely to occur over time is difficult to quantify; assumptions must be based on field or laboratory testing, current geotechnical properties, limited case studies, extrapolation and engineering judgement. The likely deterioration in the 
various components contributing to rock mass strength must be identified, including the intact strength, the joint properties and the joint spacing. These can be assessed using weathering, durability and GSI data available for the rock mass at the time of pit design - to provide amended inputs for stability assessment.

The following are suggested as design acceptance criteria for pit slope failure for closure:

- Where a predicted (analysed) failure zone intersects adjacent sensitive infrastructure elements or the minimum $10 \mathrm{~m}$ standoff distance therefrom, a FoS of $\geq 1.5$ should be achieved under static conditions and a FoS of $\geq 1.1$ should be achieved under dynamic conditions (taken as the upper bound of the FoS range for high risk for slope stability in Table 1).

- Where a predicted failure zone is of limited extent such that it does not intersect the sensitive infrastructure elements or minimum $10 \mathrm{~m}$ standoff distance therefrom, then the FoS is not important (i.e. failure within this zone is considered to be acceptable over the long-term).

If assessments indicate that failure of pit slopes after closure presents an unacceptable risk to nearby infrastructure, the occurrence of failure must be mitigated. Ground support and/or maintenance of depressurisation is not an acceptable solution for the long-term. If infrastructure cannot be re-positioned, the use of in-pit buttressing for slope support represents one of the few practical solutions. In-pit buttressing measures necessary to reduce the risk or size/extent of failures must then be designed.

\section{References}

Department of Minerals and Energy, Western Australia 1999, Geotechnical Considerations in Open Pit Mines - Guideline, Version 1.0. Department of Mines and Petroleum, Western Australia 1997, Safety Bund Walls Around Abandoned Open Pit Mines - Guideline, Revision 1.0, Document ZMA048HA.

Earth Resources 2019, Guidelines for the assessment of geotechnical risks in open pit mines and quarries, Victoria State Government, Department of Jobs, Precincts and Regions website, page updated 13 May 2019, https://earthresources.vic. gov.au/legislation-and-regulations/guidelines-and-codes-of-practice/guidelines-assessment-of-geotechnical-risks-in-openpit-mines-and-quarries

Hoek, E \& Brown, E 1988, 'The Hoek-Brown failure criterion - a 1988 update', in JH Curran (ed.), Proceedings of 15th Canadian Rock Mechanics Symposium, Toronto, pp. 31-38.

Marinos, P \& Hoek, E 2000, 'GSI: a geological friendly tool for rock mass strength estimation', Proceedings of the International Conference on Geotechnical and Geological Engineering, GeoEng 2000, International Society for Rock Mechanics, Lancaster, pp. 1422-1446.

Read, J \& Stacey, P (eds) 2009, Guidelines for Open Pit Slope Design, CSIRO Publishing, Collingwood.

van Zyl, D 2009, 'Open pit closure', in J Read and P Stacey (eds), Guidelines for Open Pit Slope Design, CSIRO Publishing, Collingwood. 